\title{
CONTENT BASED INSTRUCTION IN THE FOREIGN LANGUAGE CLASSROOM: CHALLENGES AND BARRIERS IN THE CONTEXT OF AN AMERICAN PUBLIC SCHOOL OF THE STATE OF MASSACHUSETTS
}

\author{
Ana Henriques \\ Harris Academy, MfL Teacher (United Kingdom)
}

\begin{abstract}
This article examines content-based instruction (CBI) as a didactic methodology for the teaching of foreign languages in a North American public school in the state of Massachusetts. It gives an account of the difficulties experienced by a group of teachers in the implementation of this methodology.

Currently, there is a significant amount of literature which supports CBI as a teaching method. However, few studies are focusing on the actual working conditions of teachers and what happens in the classrooms where this method is followed. Whereas research in language teaching didactics has allowed for critical analysis of this method, it has not accounted for the difficulties and doubts teachers face. Therefore, this study focused on teachers' evaluations and suggestions. For this purpose, the authors conducted interviews, analysed lesson plans and didactic materials and also administered a critical evaluation of the students' proficiency in the target language.

This study identified the handicaps and risks of this methodology. It also highlighted that the way used to implement this product in this school required an effort on the part of teachers, which did not, in any way, translate into benefits for the students.

This study is comprised of four stages:

1) Theoretical foundations of the CBI methodology;

2) Analysis of Teachers' Feedback and perspective;

3) Language ideology in a neoliberal context of data-driven and increased privatization of Education;

4) Final considerations and suggestion of possible future research needs;

This research is of particular interest in Portugal where there is a robust governmental push for empowering councils across the country to take charge of their educational needs. This paper sheds light on areas such as autonomy and school innovation, leadership in education and the definition of the concept of being a teacher. It is also relevant for any entity interested in related issues due to curricular changes, together with the professional well-being and stability of the teaching staff.
\end{abstract}

Keywords: Content and language-integrated learning (clil), classroom discourse, bilingualism, leadership, critical thinking.

\section{Introduction}

Currently, there is a significant amount of literature, which supports CBI as a teaching method. However, few studies are focusing on the actual working conditions of teachers and what happens in the classrooms where this method is followed. Whereas research in language teaching didactics has allowed for critical analysis of this method, it has not accounted for the difficulties and doubts educators face when teaching a foreign language course that draws on a vast academic curriculum. The lack of subject knowledge and pedagogical approaches to academic content that traditionally was not in the domain of foreign language lessons is a crucial concern presented. In this sense, it is postulated as the primary objective of this study to understand the difficulties experienced in the classroom during the CBI implementation process and to understand the reasons for refusing what was presented as a methodological novelty.

Therefore, this is a qualitative study that pretends to analyse and interpret teachers' discursive features and practices aiming to provide a close view of the implementation of a methodological transition carried out in a particular school. For that, four teachers were interviewed: one Latin, two 
Spanish and finally one Portuguese teacher. Curriculum mapping was analysed, and lesson observation took place.

Finally, is it relevant to reinforce that this study wants to exclude generalizations over other teachers that use a similar methodology. However, the problematic and the discussion presented may be transferable to other educational sceneries and may shed light on the educational field.

\section{The issue}

What happens inside of a classroom is critical for the process of teaching and learning. It is not relevant to present a theoretically well-founded methodology if teachers do not have the conditions to develop it. Theo Boland and Jos Letschert (1995) argue that "the heart of the curriculum (...) is the classroom where the teacher-student interactions take place." Therefore, although the reference literature indicates potential benefits for learning a foreign language following the theoretical model Content Based Instruction, it is necessary to understand the particular conditions in which this method is developed and applied.

Foreign language teachers (FL) are usually focused on the linguistic, cultural and communicative dimension of the language they teach. The programs are organized in relevant thematic contents that allow to study the culture, to understand the structure of the language and consequently to develop communicative skills. However, the foreign language is also a discipline in the humanities area and, therefore, it also has other responsibilities:

- the ability to critically examine one's cultural ideas and traditions;

- the ability to see oneself, not only as a citizen belonging to a nation but also as human beings connected to others by bonds of recognition and mutual concern;

- a narrative imagination that allows the individual to put himself in the place of the other; (Not for Profit 2010) by Martha Nussbaum.

One can easily verify the multitude of aspects that need to be considered when organizing and creating a curriculum for the languages, as well as the breadth of knowledge and sensitivity of the educators who teach these curricula. Besides, there has never been such a more significant debate and tension between what is taught in the classroom and what society believes students will need once out of school. The world is changing to such an extent that language teachers are asking for what is supposed to be taught. Nevertheless, the choice of the CBI model does not impede, neither ignore, this language teaching problematics. According to Stryker (1997) "CBI can be refreshing and liberating for both teacher and students (...) more a philosophy than a methodology, there is no singular form for CBI."

However, during the operationalization process of creating and delivering the curriculum, difficulties arose, and not all teachers were able to adapt. Some of them have left the school arguing their inability to adapt to the requirements of the method. Therefore, the central research question of this study was: How is content-based instruction carried out discursively by a group of teachers in a world language department and their feelings affected their professional wellbeing and learning environment in their classes.

\section{Theoretical fundamentals of CBI}

North American research has presented CBI as a model to follow for the teaching of Foreign Language (FL). Stoller (1997) presents this method as being a natural approach to LE learning. Curtain and Pesola (1994) demonstrates the benefits of teaching thematic contents as a vehicle of language learning. Krashen, Swain and Cummins, authors of much of the theory behind the implementation of CBI, after having analysed the immersion programs of Canada and the United States, argue that students learn more effectively if intensely exposed to a foreign language.

In fact, since its introduction in Foreign Language Annals (Leaver and Stryker 1989) CBI has been used in a wide variety of contexts over the last 25 years. According to the authors, this method can be characterized as (...) a philosophical orientation, a methodical system, a syllabus design for a single course, or a framework for an entire program of instruction. CBI implies the total integration of language learning and content learning. It represents a significant departure from traditional foreign language teaching methods in that language proficiency is achieved by shifting the focus of instruction from the learning of language per se to the learning as language through the study of subject matter."

It is for this reason that the CBI authors propose the construction of a curriculum centered on a topic, subject or thematic unit, which should be approached by the use of texts and other authentic materials appropriated to the interests and needs of the students. Thus, in this perspective, we can consider CBI essentially as a student-centered method that allows the teacher to resort to a great variety of working methodologies that can range from the development of research projects to cooperative or experimental teaching. 


\subsection{Key underpinnings}

1. According to CBI, we must learn a foreign language in order to involve specific contents of other subjects. The organization of the curriculum is mainly based on a thematic area to the detriment of the language itself. The student's communicative competence develops during the study process of a topic related to science, art, social studies, culture, history, politics or economics. The language used should allow natural learning as it must be understandable and relevant to the needs of the students.

2. The explicit learning of the structure of the language (grammar) happens as a pretext for communication. For this reason, the artificially created exercises for classroom situation cease to make sense. It is hoped that the teacher will be able to find authentic materials as well as create moments of reading, writing, and conversation oriented to the linguistic and cultural reality of the language being studied. In the words of Leaver and Stryker (1997) This concept is especially relevant to CBI since, in order to prepare our students to live and work in a new culture, we must create a direct link between the classroom and the culture being studied. This cannot be accomplished effectively in a program that focuses primarily on grammatical competence".

3. The development of communicative competence is essential for language learning. Fluency and linguistic rigor are seen as parallel principles. However, fluency takes on greater relevance as it is essential for the communicative process, rather than linguistic purity. In this sense, students are expected to be able to use and manipulate the language (to produce and receive) spontaneously, without previous memorization.

4. Students should have the opportunity to use what they learn in language classes to read, understand and intervene in the world. In the same way, teaching and lesson preparation must be flexible to adapt to the student's previous knowledge.

5. CBI in a very natural way must enable cooperative, experimental teaching as well as the development of research projects.

6. In a general way, CBI has excellent potential to motivate and self-implicate. Once contextualized and learner-centered, learning is achieved. Students are ready for the development of activities that must be capable of generating intrinsic motivation. Consequently, the approach of complex contents, so essential for humanistic education, happens spontaneously. Students should have the opportunity to make choices and set preferences based on the specificity of their needs and interests. There are always multiple possibilities of analysis for the same topic, and there must be freedom to explore them in a student-centered style of teaching. Therefore, there is flexibility and adaptability to build the curriculum and its sequences. Subtopics can be included, new questions raised, or objectives can be reformulated.

\section{Research findings}

Most studies about CBI instruction tended to look at the language development of students and their success in learning the subject matter. They also focus on student's motivation and its impact on language learning enthusiasm. Although there are few pieces of research based on the teacher's perspectives, theorists expected educators to implement their views of how a classroom should be. Therefore, the finding researches here presented are mostly the result of teachers discourses.

Many teachers internalized a distinction between language learning and language use. Consequently, they believe that first, students should be able to manipulate the language and, only after use it in authentic communication activities. This contradicts the CBI theory; therefore, a mindset change requires training, time, and an understanding of the process. If one of those premises fails, it is doubtful that a school will be able to implement a communicative language teaching approach (CLT), task-based language (TBLT), content-based instruction (CBI) or also called content and language integrated learning (CLIL). In this particular school, some of the teachers did not have an understanding of the theoretical underpinnings of CBI. They were invited to design curricula for teaching the language without a whole vision of what was expected. There was a lack of communication between the head of the department and the team. Generic and contradictory information given led teachers to write and rewrite the curriculum in a time-consuming process. According to teachers, the uncertainty of what the expectations were, and the regular learning walks with very critical and harsh feedback, resulted in an unmotivated team.

In order to carry out this method educators had to produce all teaching resources. As CBI requires authentic material, the biggest challenge was to research for reading, listening and visual resources for the student's age level. The disparity of themes worked in the classroom, forced a continuous investigation without real conditions to succeed. During interviews teachers explained that some of the resources were produced under pressure and, as a consequence, decontextualized and inaccurate information was delivered to students, which created a disbelief of their value as teachers. 
During the process of writing the curriculum, two forces were contradictory: the tension between the whiling to understand languages and cultures under the dynamism of globalization and, on the other side, the reinforcement of nationalism as a centripetal force. Thus, the significance of learning Spanish became a field of dispute: in one hand, teachers defending language as a cultural capital of independent and critical thinking. In some cases, discussing the role of the United States in the world and questioning the establishment. On the other hand, the teaching of linguistic and content information transformed into goods or emphasising a positive appraisal of the American culture. This group of teachers assumed the learning of Spanish as an "added value" for traveling abroad, or as an eventual future professional valuable skill. On this approach, teaching the language was based on what teachers considered universal shared values, ignoring concepts of diversity intercultural perspective or critical thinking. The analyses of teaching material and lesson observation showed learning moments of prejudice reinforcement towards other societies.

It was also possible to verify a significant concern related to class management and indiscipline control or unproductiveness, which contradicts the idea of intrinsic motivation. Part of this reality has to do with how students are distributed across classes. Although the district offers Portuguese and Spanish courses since elementary school, going up to level 5 in secondary, it cannot be guaranteed that all students will do the same course linearly. New students in town, emigrants arriving, or students changing classes produced a great disparity of ages, experiences, and interests. In this scenario differentiation would have been key to the success of the program, however big classes and lack of support made it impossible.

The implementation of CBI under these conditions resulted in a violent psychological working environment that caused an embarrassing teacher turnover: seven teachers abandoned school in less than four years. Students talked about "the curst of Wold Language Department" and bet for "the next to fall." Teaching conditions in the classroom were each week more challenging to overcome.

\section{Future research needs}

CBI has considerable potential and may be part of the solution to the problems of articulation of foreign language and other departments. Thus, it would be interesting a comparative study with a European school that has adopted CLIL as a methodology. Since one of the biggest concerns in the school referred in this paper was the difficulty of finding authentic material, how could this group of teacher benefit from teaching a program in which part of the material was already prepared and ready to use in a textbook.

\section{References}

Boland, Theo \& Letschert, Jos (1995); Primary prospects - Developments in Primary Education in some European Countries. The Netherlandas: SLO

Leaver, Betty Lou; Stryker, Stephen (1989) Foreign Language Annals, v22 n3 p269-75 May,

Nussbaum, Marta (2000) Not for Profit why democracy needs humanities, Princeton University Press, New Jersey;

Snow, Marguerite Ann \& Brinton Donna, Content Based Classroom, Perspectives on integrating Language and Content, 1997, White Plains

Stryker, Stephen \& Leaver, Betty Lou (1997) Content based instruction in foreign Language Education, Models and Methods, 